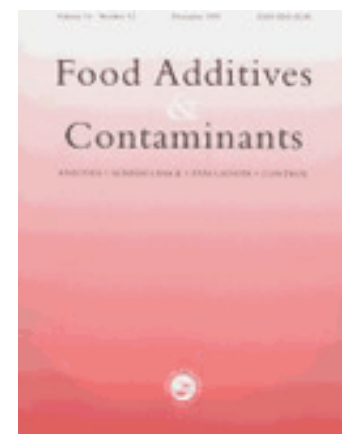

\title{
OCCURRENCE OF HALOANISOLE AND HALOPHENOL CONTAMINATION IN AGED RED WINES
}

\begin{tabular}{|r|l|}
\hline Journal: & Food Additives and Contaminants \\
\hline Manuscript ID: & TFAC-2008-049.R1 \\
\hline Manuscript Type: & Original Research Paper \\
\hline Author: & 04-Jun-2008 \\
\hline Complete List of Authors: & $\begin{array}{l}\text { Copete, Ma Luisa; Universidad Castilla-La Mancha, Ciencia y } \\
\text { Tecnología Agroforestal } \\
\text { Zalacain, Amaya; Universidad Castilla-La Mancha, Ciencia y } \\
\text { Tecnología Agroforestal } \\
\text { Lorenzo, Cándida; Universidad Castilla-La Mancha, Ciencia y } \\
\text { Tecnología Agroforestal } \\
\text { Carot, Jose; Universidad Politécnica de Valencia } \\
\text { Esteve, Ma Dolores; Universidad Poltecnica de Valencia, Química } \\
\text { Climent, Ma Dolores; Universidad Poltecnica de Valencia, Química } \\
\text { Salinas, Ma Rosario; Universidad Castilla-La Mancha, Ciencia y } \\
\text { Tecnología Agroforestal }\end{array}$ \\
\hline Methods/Techniques: & Chromatography - GC/MS, Extraction, Toxicology \\
\hline Additives/Contaminants: & Environmental contaminants, Pesticides - organochlorine \\
\hline Food Types: & Wine \\
\hline & \\
\hline
\end{tabular}

\section{SCHOLARONE \\ Manuscripts}




\title{
1 OCCURRENCE OF HALOANISOLE
} 2 CONTAMINATION IN AGED RED WINES

3

4

\author{
M.L.Copete ${ }^{1}$, A. Zalacain ${ }^{1}$, C. Lorenzo ${ }^{1}$, J.M. Carot ${ }^{2}, \mathrm{M}^{\mathrm{a}}$ D. Esteve ${ }^{3}, \mathrm{M}^{\mathrm{a}}$ Climent $^{3}$, M.R.
} Salinas $^{1 *}$

${ }^{1}$ Cátedra de Química Agrícola, ETSIA, Universidad de Castilla-La Mancha, Albacete, Spain.

${ }^{2}$ Departamento de Estadística e Investigación Operativa Aplicadas y Calidad, ETSII, Universidad Politécnica de Valencia, Spain.

3 Departamento de Química. Universidad Politécnica de Valencia, Valencia, Spain.

*Rosario.Salinas@uclm.es

\section{Abstract}

This exhaustive study is the first to be carried out on the incidence of halophenols and haloanisoles in aged red wines, not only in terms of trichloroanisole. Nine hundred and sixtysix red wines of different ageing times (6, 12 and 24 months in oak barrels) and different Spanish production areas were analysed by stir bar sorptive extraction followed by GC/MS. From the total sampling, $155(16.1 \%)$ wines were contaminated with one or several compounds, with $7.6 \%$ of these corresponding to the aged-12 wine category, $6.9 \%$ to the aged-6 group and the rest to the aged-24 wines (1.5\%). The most abundant compounds causing taint were 2,3,4,6-tetrachloroanisole and 2,4,6-trichloroanisol (6.8 and $5.3 \%$, respectively). No 2,4,6-tribromophenol was found in any of the samples. The contamination with halo- compounds was highest in the samples from the South-West of Spain, followed by those from the North. The mean concentration found for all compounds are always higher than their respective olfactory threshold, but neither of these halo compounds represent a health hazard to human subjects through the consumption of commercial red aged wines.

Keywords: Contamination, Haloanisoles, Halophenols, Aged red wine 


\section{Introduction}

2

3 Musty taint, traditionally known as "cork taint", is a serious problem for both wine and cork

4 industries worldwide. This flavour-damaging effect is usually perceived as a mouldy, musty and/or earthy aroma that may mask the natural wine aroma and lessen its quality (Amon et al., 1989; Butzke et al., 1999; Fuller, 1995; Peña-Neira et al., 2000; Mazzoleni and Maggi et al., 2007). Although different compounds have been identified in relation to this alteration (guaiacol, geosmine or 2-metilisoborneol among others) (Maga, 1978), most authors agree that halophenols and haloanisoles, particularly chloroanisoles, are the primary compounds responsible for this problem (Butzke et al., 1999; Chatonnet et al., 2004; Silva-Pereira et al., 2000; Rubio-Coque et al. 2006). Other compounds such as 2,4,6-tribromoanisole (TBA) can be responsible for the "cork taint" when insufficient amounts of TCA or other chloroanisoles are detected in wines (Chatonnet et al., 2004).

Traditionally, and erroneously, the wine contamination with this off-flavour has been associated with the cork, and therefore the inappropriate used of the term "cork taint" has contributed to the spreading of the idea that contamination with chloroanisoles is always attributed to the cork stopper. Scientific data have shown that the true origin of the wine contamination by halophenols and haloanisoles is in fact a problem of environmental contamination. Blaming the cork stopper almost exclusively is too simplistic as there are many different sources of contamination. In fact, in some cellars, it is possible to detect contaminated wines that have never been in contact with cork, thus attributing the problem to other enological products that have been in contact with chlorine derivatives used as pesticides or cleaning products such as hypochlorite-based disinfectants (Chatonnet et al. 2004). These volatiles are easily transmitted through the air, and show a great capability for adhering and contaminating wood, cork and many other materials (plastic polymers, silicons, cardboard and paper, etc). Most studies also deal with chloroanisoles, especially TCA, due to their low olfactory thresholds, but chlorophenols are as important as they are considered their precursors. Chlorophenols may originate in several ways, the most accepted hypothesis being the O-methylation reaction by different microorganisms (especially fungi) (ÁlvarezRodriguez et al., 2002; Riu et al., 2002; Maggi et al., 2008). Many different microbes, e.g. common moulds such as Penicillium, Aspergillus, Trichoderma and even Botrytis cinerea can generate haloanisoles from halophenols (Lee and Simpson, 1993; Maggi et al., 2008). The most used halophenols have been especially pentachlorophenol (PCP) and 2,4,6- 
1 trichlorophenol (TCP), which have been used as pesticides, although they were forbidden in 2 the European Union several years ago. However, they can persist in the ecosystems for a very 3 long time (Rubio-Coque et al., 2006). This problem also affects human health since the 4 precursors are considered as highly toxic (Armstrong et al., 1993; Fahrig et al., 1978; Jansson and Jansson, 1992; Hattula and Knuutinen, 1985; McGregor et al., 1988; Ono et al., 1992).

6 Yet, international legislation only limits the content of some halophenols in drinking water (5 $7 \mu \mathrm{g} / \mathrm{L}$ in TCP) (Iris, 1994), with nothing being said about haloanisoles. Soleas et al. (2002) carried out a cytotoxicity study using TCA and TCP standard solutions up to a concentration of $500 \mu \mathrm{g} / \mathrm{L}$, with neither TCA nor TCP adversely affecting the viability of any of the cells lines tested.

12 Despite being a great cause for concern for the wineries all around the world, there are many 13 discrepancies about its real incidence, and the quantification of the economic losses produced 14 by the contamination from these compounds. Most studies refer to TCA, and percentages greater that the 7\% have been not shown (Butzke et al., 1999; Fuller, 1995; Lee and Simpson, 1993; Pollnitz et al., 1996; Soleas et al. 2002). In the most exhaustive study, carried out by Soleas et al. (2002), a panel of experts analysed more than 2,400 different wines from several countries. The overall incidence of "cork taint", only measured in terms of TCA, was $6.1 \%$, 19 but those wines closed with composite corks demonstrated an incidence of $31.9 \%$. Differences were also observed between white and red wines with an incidence of $8.3 \%$ and 4.2\%, respectively. Among red wines, the highest incidence was observed for Portugal (6.7\%) and Spain $(6.5 \%)$, although only the $12.6 \%$ of the total sampling came from those two countries.

For all these reasons, the occurrence of halophenols and haloanisoles, not only TCA, in nine26 hundred and sixty-six Spanish aged red wines has been analysed using SBSE-GC-MS. The presence of the target compounds has been related to the different wine production areas and other oenological parameters. Additionally, an estimation of halophenol and haloanisole ingestion by Spanish red wine consumers has been carried out.

\section{Chemicals and reagents}


1 Standards:

2,3,4,5,6-pentachloroanisole;

2,3,4,6-tetrachlorophenol;

$2,3,4,6-$

2 tetrachloroanisole; 2,4,6-tribromoanisole; 2,4,6-tribromophenol; 2,4,6-trichloroanisole;

3 2,4,6-trichlorophenol were obtained from Sigma-Aldrich (Madrid, Spain) and

4 pentachloroanisole from LGC Promochem (Molsheim, France). Exact masses of the chemical

5 standards were dissolved in absolute ethanol.

6

Solvents: ethanol (analytical-reagent grade) was obtained from Merk (Damstard, Germany), while water was purified through a Milli-Q system (Millipore, Bedfords, MA, USA). Synthetic wine samples were prepared by an ethanol solution at $12 \%$ (v/v) to which $5 \mathrm{~g} / \mathrm{l}$ tartaric acid were added. Solution $\mathrm{pH}$ was adjusted to 3.6 with $1 \mathrm{M}$ sodium hydroxide (Panreac, Barcelona, Spain).

\section{Classical Oenological parameter analysis}

The classic analyses of must and wines were performed according to the official methods established by the ECC (1990). The following parameters were analysed: pH, alcohol degree, and total acidity.

\section{Stir Bar Sorptive Extraction (SBSE)}

Compounds were extracted by introducing the polydimethylsiloxane coated stir bar $(0.5 \mathrm{~mm}$ film thickness, $10 \mathrm{~mm}$ length, Twister, Gerstel, Mülheim and der Ruhr, Germany) into $10 \mathrm{ml}$ of sample (either commercial wine or synthetic wine solution), to which $100 \mu$ l of internal standard $\gamma$-hexalactone solution at $6 \mu 1 / 1$ in absolute ethanol was added. Samples were stirred at $700 \mathrm{rpm}$ at room temperature for $60 \mathrm{~min}$. The stir bar was then removed from the sample, rinsed with distilled water and dried with a cellulose tissue, and later transferred into a thermal desorption tube for GC/MS analysis (Zalacain et al., 2004).

\section{TD-GC/MS analysis}

The thermal desorption equipment (ATD 400 of Perkin-Elmer, Norwalk, USA) was coupled to the gas chromatograph. The stir bar was introduced into the thermal desorption tube and the volatile compounds were desorbed from the stir bar at the following conditions: oven temperature at $330{ }^{\circ} \mathrm{C}$; desorption time, 4 min; cold trap temperature, $-30{ }^{\circ} \mathrm{C}$; helium inlet flow $45 \mathrm{ml} / \mathrm{min}$. The compounds were transferred into the Hewlett-Packard 6890 gas 
1 chromatograph coupled to an Hewlett-Packard mass detector (Palo Alto, USA) with a fused 2 silica capillary column (BP21 stationary phase $50 \mathrm{~m}$ length, $0.22 \mathrm{~mm}$ i.d., and $0.25 \mu \mathrm{m}$ film 3 thickness) (SGE, Ringwood, Australia). The chromatographic program was set at $50{ }^{\circ} \mathrm{C}$ (held 4 for $5 \mathrm{~min}$ ), raised to $180{ }^{\circ} \mathrm{C}$ at $2.5^{\circ} \mathrm{C} / \mathrm{min}$ (held for $2 \mathrm{~min}$ ) and to $230^{\circ} \mathrm{C}\left(5^{\circ} \mathrm{C} / \mathrm{min}\right)$ and held for $20 \mathrm{~min}$. For mass spectrometry analysis, electron impact mode (EI) at $70 \mathrm{eV}$ was used. The mass range varied from 35 to $500 \mathrm{u}$ and the detector temperature was $150{ }^{\circ} \mathrm{C}$. Identification was carried out by comparing with their respective standards and using the NIST library. Quantification was carried out by using the extracted ion mode. with their respective $\mathrm{m} / \mathrm{z}$, and it was based on the calibration curves of standards in the synthetic wines

\section{Wine Samples}

13 One of the most tedious tasks of this study was the selection of samples, as the authors wanted

For this study, only aged red wines of the highest quality have been chosen. According to the Spanish legislation and in agreement with the Regulatory Council for Origin Appellations, 
1 time in oak barrels of 6,12 and 24 months, all of which require another period in bottle before

2 being eligible for sale at 18, 24 and 36 months, respectively. The total number of samples

3 analysed were 966 quality Spanish aged red wines from three different categories named as

4 aged-6, aged-12 and aged-24 (Table 1).

5

6 Statistical analysis

7 Data was processed by the Answer Tree 3.0, SPSS 14 and Unscrambler 9.0 using the CART 8 method (Classification And Regression Trees) which is an binary algorithm developed by 9 Breiman et al., (1984). CART divided the data into two subsets, so cases falling within each 10 of the subsets are more homogeneous than in the previous subset. It is a recursive process that 11 repeats itself until reaching the criterion of homogeneity or another criterion for stopping. The 12 13 14 15

16 Due to the discrepancies found about the impact of halophenols and haloanisoles 17 contamination in quality wines, 966 different aged red wines were analysed (Table 1). It is 18 important to point out that this study is not only concerned with TCA as most studies are, but 19 with the most important halophenols and haloanisoles related to this wine off-flavour defect 20 (Maarse et al., 1988, Tanner et al., 1981). The study has revealed that 155 wine samples were 21 contaminated with one or several compounds, which means the $16.1 \%$ of the total sampling. 22 Of these 155 tainted cases, the $7.6 \%$ correspond to the aged-12 wines category, the $6.9 \%$ were 23 aged-6 and the rest were aged-24 wines (1.5\%). This tendency is not related with the 24 wineries' belief that the longer the time in the oak barrels, the higher the possibility of 25 26 27 28 29 30 31 32 
1 As it can be observed in Table 2, from the seven target compounds analysed, TCA and TeCA 2 were the most abundant, $5.3 \%$ and $6.8 \%$ respectively, followed by TCP. The higher 3 percentage of TeCA and TCP is quite surprising, as both are potential precursors of TCA 4 although conversion takes place through different pathways (Maarse et al., 1988, Tanner et al., 1981). The higher occurrence of the tainting compounds was observed in aged-12 red wine (Table 3). Looking at Table 2, it is worthy of mention that in area 3, the most contaminated area, no TCA or TeCA was detected, but PCA (12.5\%) and specially TCP (25\%) were found. Those wines may be not be rejected by wine consumers for the moment as TCP and PCA olfactory thresholds are higher than TCA, but their evolution is of great importance in terms of TCP conversion into TCA. Area 6 has a 18.2\% of their total wine sampling, with TeCA being the most abundant compound (9.3\%) followed by TCA (5.9\%), and with PCA, TCP and TBA (Table 2) showing lower values. The $16.1 \%$ of the wines analysed for area 1 have shown TCP as the one with the highest percentage (8.8\%), whereas 14 the remaining compounds (TCA, TeCA, PCA and TBA) do not surpass the $3.6 \%$. In area 4 , 15 although the percentage of contamination is lower (11.5\%) than area 6, the type of 16 compounds found and the frequency at which they are detected are similar. In this case, TeCA is the most abundant haloanisole, followed by TCA, while under $4 \%$ of the wines analysed are contaminated with the other tainting compounds. Lastly, in area 2 showed a contamination of $9.8 \%$, with TCA the most abundant (4.5\%). Below 3\%, TeCA, PCA and TCP are detected. Special mention should be made for TBA and TBP contamination, as Chatonnet et al., (2004) indicated that both compounds seem mainly to derive mainly from environmental pollution in wineries. TBP derivatives are often used as flame retardants in a broad range of materials, thus raising the risk of pollution. In this study, TBP has not been found in any of the wines analysed, but TBA has always been detected at a percentage lower than $3 \%$.

A uniform contamination distribution in terms of geographical areas can be observed, as areas 1 and 6 are grouped within the northern zone of Spain followed by areas 2 and 4 which corresponded with the east-central zone of the Spanish mainland. It is not possible to affirm that cork stoppers are the only elements responsible for such contamination, as the contamination pattern found within this sampling in terms of wine production areas is not in accordance with such an affirmation. This does not mean that wineries from the north of Spain use stoppers of poorer quality than, for example, the centre-east. Such taint distribution, south-west of Spain (area 3) > northern (area 1 and 6) > centre-east (areas 2 and 4) may be attributed to the effect of the environmental conditions on the microorganism propagation 
1 when are exposed to polluted zones of halophenols in the wineries (Rubio-Coque et al., 2 2006). The westen (area 3) and northern (areas 1 and 6) parts of Spain are characterized by 3 their high humidity conditions (MAPA, 2004) (Table 4). The size of the microbial population 4 significantly increases with humidity (Alvarez-Rodriguez et al. 2002), and may justify why 5 these areas are the most contaminated of course if enough sources of precursors are present. 6 Evidently it is not possible to conclude that the humidity conditions are the only responsible 7 for the higher contamination, but wooden deposit use for winemaking in some cellars of these areas may be important on this occurrence.

In addition, the mean concentration of the compounds found in the contaminated wines are higher than their respective olfactory thresholds (Table 5), which means that consumers will perceived them with clarity in taste and smell, and therefore reject those wines. Such high concentrations suggest that cork stoppers are not the only factor responsible for this wine offflavour, along with the fact that cork factories have diminished TCA by about $75 \%$ in recent years, a consequence of the many controls adapted to avoid such contamination (RubioCoque et al., 2006). Other studies reveal as well that cork stoppers can only contaminate the wine when the haloanisoles are located on the surface in contact with the wine (Pollintz et al., 1996). However, Capone et al. $(1999,2002)$ goes further by stating that only occasionally does more than the $10 \%$ of the TCA from the cork leach into the bottled wine and, in most cases, TCA cork does not leach into wine at all. In this way, the concentration found in the wines is again too high to be transferred from the cork stopper (Table 5).

Consumers are an important part of this problem. In 2004/05 red wine from OD was bought in 8,191,603 Spanish households, i.e. 55.5\% of the total national, with areas 4 and 6 having the highest consumption percentage, 24.4 and $54.1 \%$ respectively (Table 6). For each purchase, 1.81 of wine per person/month is calculated (MAPA, 2004). The average size of a Spanish household is 2.9 persons and, when considering the average consumption of red wine with OD and the average number of occupants per home, a common wine consumer will drink an average of $8.81 /$ year. If this consumption data is related to the occurrence of halophenols and haloanisoles in aged red wines presented in Table 1 and considering the only toxicity normative available for TCP, $5 \mu \mathrm{g} \mathrm{L}^{-1}$ in drinking water for TCP is acceptable, the mean concentration of tainting compounds found in those wines will never be a problem for quality red wine consumers, even if they are unfortunate enough to only buy contaminated wines from areas 1, 3 and 6 . If these results are compared with a previous study done by 
Soleas et al., (2002) where the concentration limits are fixed at $500 \mu \mathrm{g} / \mathrm{L}$ (TCA and TCP),

2 then we could conclude that neither of these halo compounds represent a health hazard to

3 human subjects through the consumption of commercial aged red wines. It is important to

4 point out that no other toxicity information has been found in relation to the other halophenols and haloanisoles in any other matrixes, and of course not in wines, leaving an via open for future research.

In order to get more information about the incidence on this problem, another statistical analysis was carried out including decision trees which related the percentage of contaminated wines with the areas studied, together with the aged wine categories (Figure 1). The first division is carried out according to the wine age category, finding significant differences between the aged-12 wines $(20.7 \%)$ and the other two aged wine categories (aged-6 and aged-24 wines, $13.4 \%$ ). Looking first at aged-12 wines, there is a variability which takes into account the geographical wine areas, where areas 1 and 6 (northern Spain) were the most contaminated $(23.5 \%)$ followed by $12.9 \%$ in the remaining wine making areas. In relation to the other group of aged wines (6 and 24-aged), the statistical analysis revealed significant differences between the area 3 and the other areas studied, confirming the early data discussed. In fact, the $50 \%$ of the analysed wines from area 3 have any of the haloanisoles and halophenols studied, while this percentage is not higher than the $12.7 \%$ for the rest of the areas.

Classical wine parameters such as $\mathrm{pH}$, total acidity and alcoholic degree were used within the decision trees as differentiating variables for contaminated wines in order to obtain more information about their possible effect on the wines. As there was too much data to process for each parameter, four sub-groups have been differentiated according to: alcohol (11-11.9\%, $12-12.9 \%, 13-13.9 \%$ and $14-14.9 \%) ; \mathrm{pH}(<3.2,3.2-3.4,3.4-3.6,>3.6)$ and total acidity (between 4-4.9, 5-5.9, 6-6.9 and 7-7.9 g/l of tartaric acid). But no correlation was found and therefore no decision tree was shown. The same results were obtained by other authors when the extraction of TCA at different alcohol degrees was followed, but no conclusions could be obtained as the opposing effects of increased TCA extraction and loss of TCA volatility at high ethanol levels tend to cancel each other out (Hervé et al., 1999). This same effect is likely to hold for sensory analysis as well, as Mazzoleni and Maggi (2007) carried out an exhaustive sensory analysis and confirm that the detection level of TCA in red wines cannot 
1 be correlated with analytical parameters such as character ethanol, sugar content, $\mathrm{pH}$, and

2 total acidity, whereas a positive differentiation can be carried out with white wines.

3

\section{Conclusions}

5 This exhaustive study is the first to be carried out on the incidence of all halophenols and

6 haloanisoles in red aged wines, and not only in terms of TCA. The study has revealed that

$7 \quad 16.1 \%$ of the total wine sampling was contaminated with one or several compounds, with the

8 most contaminated wines being those aged for at least 12 months, followed by aged- 6 and

9 aged-24 months wines. Although the most abundant tainting compounds are TeCA and TCA,

10 special attention should be given to the high concentrations of TCP, precursor of TCA. Due to

11 the mean concentration of tainting compounds and the geographical areas distribution, the

12 cork stopper is not the only factor responsible for such taint incidence since the south-western

13 and northern areas of the Spanish mainland are the most contaminated, coinciding with the

14 areas with the highest humidity conditions, ideal conditions for microorganism propagation.

15 However, other sources of contaminations to be taking into account in these areas can be the 16 wooden materials used during winemaking. Despite their possible economic damage to the 17 wine industry, even the highest concentration encountered in commercial aged red wines is 18 several orders of magnitude below the levels that may be harmful to human health.

\section{References}

21 AcNielsen, 2004. Análisis de mercado del vino tinto con denominación de origen. Informe restringido.

23 Álvarez-Rodriguez MA, López-Ocaña L, López Coronado JM, Rodríguez E, Martínez MJ, 24 Larriba GR, Rubio-Coque JJ. 2002. Cork Taint of Wines: Role of the filamentous fungi 25 isolated from cork in the formation of 2,4,6-trichloroanisole by o-methylation of 2,4,626 trichlorophenol. Appl Environ Microbiol. 68:5860-5869.

27 Amon JM, Vandeepeer JM, Simpson RF. 1989. Compounds responsible for cork taint. Aust $28 \quad$ NZ Wine Ind J. 4:62-69.

29 Armstrong MJ, Galloway SM, Ashby J. 1993. 2,4,6-trichlorophenol (TCP) induces 30 chromosome breakage and aneuploidy in vitro. Mut Res. 303:101-108.

31 Breiman L, Friedman JH, Olshen RA, Stone CJ. 1984. Classification and regression trees. 32 Belmont, California: Wadsworth. 
1 Butzke CE, Evans TJ, Ebeler SE. 1999. Detection of cork taint in wine using automated solid2 phase microextraction in combination with GC/MS-SIM. ACS Symp Series 714:208-216.

3 Capone DL, Skouroumounis G.K, Barker D.A, Mclean H.J, Pollnitz A.P, Sefton M.A. 1999.

Absortion of chloroanisoles from wine by corks and by other materials. Aust J Grape Wine Res. 5:91-98

Capone DL, SkouroumounisG.K, Sefton MA. 2002. Permeation of 2,4,6-trichloroaniles through corks closures in wine bottles. Aust J Grape Wine Res. 8:196-199

Chatonnet P, Bonnet S, Boutou S, Labadie MD. 2004. Identification and responsibility of 2,4,6-tribromoanisole in musty, corked odors in wine. J Agric Food Chem 52:1255-1262.

ECC.1990. Commission Regulation VO 2676/90 concerning the establishment of common analytical methods in the sector of wine. Off J Eur Commun L272 (3):1-192.

Fahrig R, Nilsson C, Rappe C. 1978. Genetic activity of chlorophenols and chlorophenol impurities. Environ Sci Res. 12:325-338.

Fuller, P. 1995. Cork taint: closing in on an industry problem. Aust. NZ Wine Ind J. 10: 5860.

Hattula ML, Knuutinen J. 1985. Mutagenesis of mammalian cells in culture by chlorophenols, chlorocatechols and chloroguaiacols. Chemosphere 14:1617-1625.

Hervé E, Price S, Burns G, Weber P. 1999. TCA in corks, cork soaks and bottled wine, ASEV Annual Meeting, Enology Session 7/2/99, Reno, Nevada.

Iris.1994. Integrated Risk Information System. U.S. Environmental Protection Agency Washington, DC.

Jansson K, Jansson V. 1992. Genotoxicity of 2,4,6-trichlorophenol in v79 Chinese hamster cells. Mut Res. 280:175-179.

Lee T, Simpson R. 1993. Microbiology and chemistry of cork taints in wine. In: Fleet GH, editor. Wine Microbiology and Biotechnology. Hardwood Academic Publishers, Fugelsang. p. 353.

Maarse H, Nijssen LM, Angelino SAGF. 1988. Halogenated phenols and chloroanisoles: occurrence, formation and prevention. In: Characterisation, Production and Application of Food Flavours. Rothe M. editor, Berlin: Akademic Verlag, p. 43.

Maga JA. 1978. Simple phenol and phenolic compounds in food flavour. Crit Rev Food Sci. $10: 323-372$. 
1 Maggi L, Mazzoleni V, Fumi MD, Salinas M R. 2008. Transformation ability of fungi isolated from cork and grape to produce 2,4,6-trichloroanisole from 2,4,6-trichlorophenol. Food Add Contam. DOI: 10.1080/02652030701522991

MAPA, 2004. Distribución, Consumo y Comercialización de vinos tintos VCPRD. Ediciones Ministerio de Agricultura, Pesca y Alimentación. Madrid, Spain.

Mazzoleni V, Maggi L. 2007. Effect of wine style on the perception of 2,4,6-trichloroanisole, a compound related to cork taint in wine. Food Res Int. 40(6):694-699.

McGregor DB, Brown A, Cattanach P, Edwards I, McBride D, Riach C, Caspary WJ. 1988. Responses of the L5178Y tk+/tk- mouse lymphoma cell forward mutation assay: III. 72 coded chemicals. Environ Mol Mut. 12:85-154.

Ono Y, Somiya I, Kawaguchi T. 1992. Genotoxic evaluation on aromatic organochlorine compounds by using umu test. Water Sci Tech. 26(1-2):61-69.

Peña-Neira A, Fernández De Simón B, García-Vallejo MC, Hernández T, Cadahía E, Suárez JA. 2000. Presence of cork-taint responsible compounds in wines and their cork stoppers. Eur Food Res Technol. 211:252-256.

Pollnitz AP, Pardon KH, Liacopoulos D, Skouroumounis GK, Sefton MA. 1996. The analysis of 2,4,6-trichloroanisole and other chloroanisoles in tainted wines and corks. Aust J Grape Wine Res. 2:184-190.

Riu M, Mestres M, Busto O, Guasch J. 2002. Determination of 2,4,6-trichloroanisole in wines by headspace solid-phase microextraction and gas chromatography-electron-capture detection. J Chromatogr A 977: 1-8.

Rubio-Coque JJ, Álvarez-Rodríguez ML, Goswami M, Feltrer R. 2006. Causes and origins of wine contamination by haloanisoles (chloroanisoles and bromoanisoles). Edition ASECOR.

Silva Pereira C, Figueiredo Marques JJ, San Romao MV. 2000. Cork taint in wine: scientific knowledge and public preception. A critical review. Crit Rev Microbiol. 26: 147-162.

Soleas GJ, Yan J, Seaver T, Goldberg DM. 2002. Method for the gas chromatographic assay with mass selective detection of trichloro compounds in corks and wines applied to elucidate the potential cause of cork taint. J Agric Food Chem. 50: 1032-1039.

Tanner H, Zannier C, Würdig. 1981 Zur analytischen differenzierung von muffon und korkgeschmack in wein. Schweiz. Z Obst U Weinbau. 117: 752-757.

Zalacain A, Alonso GL, Lorenzo C, Iñiguez M, Salinas MR. 2004. Stir bar sorptive extraction for the analysis of wine cork taint. J Chromatogr A. 1033:173 - 178. 
Figure 1.- Decision tree which related the percentage of contaminated wines with the studied areas and the wine

aged categories.

\section{Contaminated wines}

\begin{tabular}{|lcc|}
\hline \multicolumn{4}{|c|}{ Node 0} \\
Category & $\%$ & $\mathrm{n}$ \\
\hline$\square$ no & 83.95 & 811 \\
aes & 16.05 & 155 \\
\hline Total & $(100.00)$ & 966 \\
\hline \multicolumn{4}{c}{$\mid$} \\
\multicolumn{4}{c}{ Aged Wine Category }
\end{tabular}

Improvement $=0.0025$
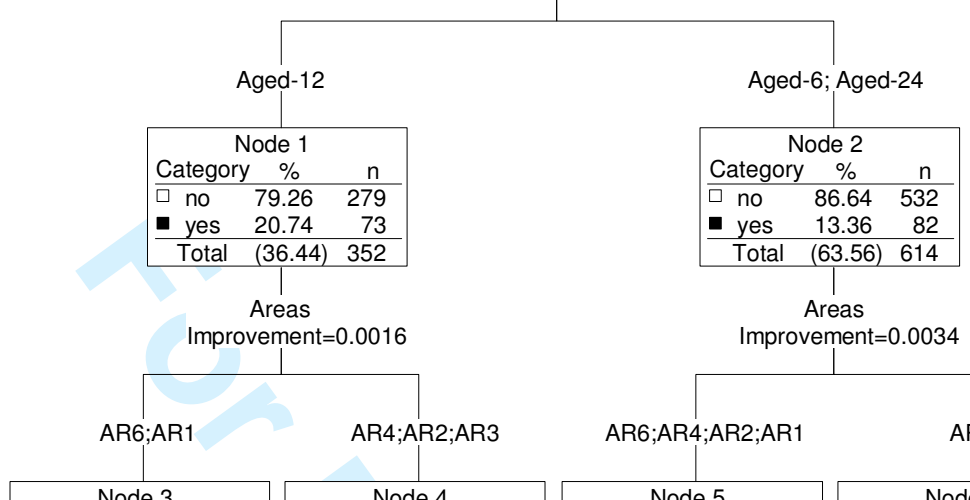

mprovement $=0.0034$

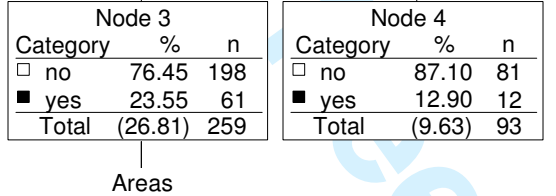

\begin{tabular}{|c|c|c|c|c|c|}
\hline \multicolumn{3}{|c|}{ Node 5} & \multicolumn{3}{|c|}{ Node 6} \\
\hline Category & $\%$ & $\mathrm{n}$ & Category & $\%$ & $\mathrm{n}$ \\
\hline$\square$ no & 87.38 & 526 & $\square$ no & 50.00 & 6 \\
\hline - yes & 12.62 & 76 & - yes & 50.00 & 6 \\
\hline Total & $(62.32$ & 602 & Total & $(1.24)$ & 12 \\
\hline
\end{tabular}

Improvement $=0.0002$

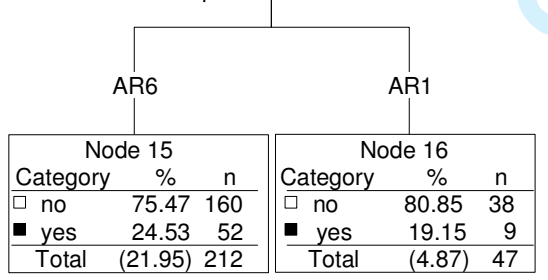


1

2

3

4

5

6

7

8

9

10

11

12

13

14

15

16

17

18

19

20

21

22

23

Table 1.- Distribution of aged red wine sampling and the percentage of contamination according to the aged wine category and geographical production area.

\begin{tabular}{|c|c|c|c|c|}
\hline \multicolumn{5}{|c|}{ Number of analysed wines } \\
\hline & Aged-6 & Aged-12 & Aged-24 & Total \\
\hline AREA 1 & 81 & 47 & 9 & 137 \\
\hline AREA 2 & 67 & 37 & 8 & 112 \\
\hline AREA 3 & 12 & 4 & 0 & 16 \\
\hline AREA 4 & 100 & 52 & 22 & 174 \\
\hline AREA 6 & 243 & 212 & 72 & 527 \\
\hline Total & $\mathbf{5 0 3}$ & $\mathbf{3 5 2}$ & $\mathbf{1 1 1}$ & $\mathbf{9 6 6}$ \\
\hline \multicolumn{7}{|c|}{ \% of Contaminated Wines } \\
\hline AREA 1 & 8.0 & 6.6 & Aged-24 & Total \\
\hline AREA 2 & 4.5 & 5.4 & 1.5 & 16.1 \\
\hline AREA 3 & 37.5 & 0 & 0 & 9.8 \\
\hline AREA 4 & 6.3 & 3.5 & 1.7 & 37.5 \\
\hline AREA 6 & 6.5 & 9.9 & 1.9 & 11.5 \\
\hline
\end{tabular}


Table 2.-Percentage of the contaminated wines depending on the area studied versus the total wine sampling

\begin{tabular}{|l|c|c|c|c|c|c|c|c|}
\hline & TCA & TeCA & PCA & TCP & TeCP & TBA & TBP & \% contaminated wines \\
\hline AREA 1 & 3.7 & 2.2 & 0.7 & 8.8 & 0 & 2.9 & 0 & 16.1 \\
\hline AREA 2 & 4.5 & 1.8 & 2.7 & 1.8 & 0 & 0 & 0 & 9.8 \\
\hline AREA 3 & 0 & 0 & 12.5 & 25.0 & 0 & 0 & 0 & 37.5 \\
\hline AREA 4 & 5.7 & 6.9 & 1.1 & 4.0 & 0.6 & 2.3 & 0 & 11.45 \\
\hline AREA 6 & 5.9 & 9.3 & 3.6 & 4.0 & 0.4 & 1.7 & 0 & 18.2 \\
\hline
\end{tabular}
(pentachloroanisole); TCP (2,4,6-trichlorophenol); TeCP (2,3,4,6-tetrachlorophenol); TBA (2,4,6-tribromoanisole); TBP (2,4,6-tribromophenol). 
Table 3.- Percentage of cork taint wines according to the different aged wine categories and the compounds found.

\begin{tabular}{|l|c|c|c|c|}
\hline Compounds & Aged-6 & Aged-12 & Aged-24 & TOTAL \\
\hline TCA & 2.1 & 7.7 & 0.8 & 5.3 \\
\hline TeCA & 2.8 & 9.0 & 1.6 & 6.8 \\
\hline PCA & 0.9 & 4.1 & 0.8 & 2.8 \\
\hline TCP & 2.7 & 4.4 & 1.1 & 4.8 \\
\hline TeCP & 0.2 & 0.3 & 0.0 & 0.3 \\
\hline TBA & 0.6 & 1.9 & 1.1 & 1.8 \\
\hline TBP & 0.0 & 0.0 & 0.0 & 0.0 \\
\hline TOTAL & 6.9 & 19.9 & 4.1 & 16.1 \\
\hline
\end{tabular}

Note: TCA (2,4,6-trichoroanisole); TeCA (2,3,4,6-tetrachloroanisole); PCA (pentachloroanisole); TCP (2,4,6-trichlorophenol); TeCP (2,3,4,6-tetrachlorophenol); TBA (2,4,6-tribromoanisole); TBP (2,4,6tribromophenol). 
Table 4.-Humidity data 2004/2005 of the different geographical production areas and the percentage of contaminated wines.

\begin{tabular}{|c|c|c|}
\hline & $\begin{array}{c}\text { Humidity } \\
\text { (mm) }\end{array}$ & \% contaminated wines \\
\hline AREA 1 & 444.6 & 16.1 \\
\hline AREA 2 & 357.5 & 9.8 \\
\hline AREA 3 & 450.0 & 37.5 \\
\hline AREA 4 & 383.6 & 11.5 \\
\hline AREA 6 & 505.2 & 18.2 \\
\hline
\end{tabular}


Table 5.- Mean concentrations of the halophenols and haloanisoles detected in the 966 quality red wines.

\begin{tabular}{|c|c|c|c|}
\hline Compounds & $\begin{array}{c}\text { OT } \\
{\left[n g L^{-1}\right]}\end{array}$ & $\begin{array}{c}\text { Mean Concentration } \\
{\left[\mathrm{ng} \mathrm{L}^{-1}\right]}\end{array}$ & $\begin{array}{r}\text { Concentration Range } \\
{\left[\mathrm{ng} \mathrm{L}^{-1}\right]}\end{array}$ \\
\hline TCA & $5-10$ & 76.5 & $546-2.6$ \\
\hline TeCA & $14-25$ & 68.4 & $775-2.2$ \\
\hline PCA & 4000 & 64.9 & $454.3-2.3$ \\
\hline TCP & Unknown & 115.3 & $521.22-4.55$ \\
\hline TeCP & Unknown & 12.5 & $30.5-.3 .4$ \\
\hline TBA & 8 & 272.5 & $847.3-10.6$ \\
\hline TBP & Unknown & 0.0 & 0 \\
\hline
\end{tabular}

(pentachloroanisole); TCP (2,4,6-trichlorophenol); TeCP (2,3,4,6-tetrachlorophenol); TBA (2,4,6-tribromoanisole); TBP (2,4,6-tribromophenol); OT (Olfactory Threshold) 
Table 6.- Red wine distribution according to the different geographical areas and relation with the contaminated wines studied.

\begin{tabular}{|l|c|c|c|}
\hline & \% Red wine consumption & \% Contaminated wines & Contaminates wines in the market \\
\hline AREA 1 & 11.8 & 16.1 & 1.9 \\
\hline AREA 2 & 9.4 & 9.8 & 0.9 \\
\hline AREA 3 & 0.3 & 37.5 & 0.1 \\
\hline AREA 4 & 24.4 & 11.5 & 2.8 \\
\hline AREA 6 & 54.1 & 18.2 & 9.9 \\
\hline
\end{tabular}

